\title{
Legal Framework Influence Towards E-Procurement Adoption Model in Developing Countries: Buyers' - Suppliers' Perception in Tanzania
}

\author{
Deus N. Shatta ${ }^{*}$, John N. Layaa $^{2}$ and France Shayo ${ }^{3}$ \\ ${ }^{1}$ Ph.D candidate at Open University of Tanzania \\ ${ }^{2} \mathrm{Ph}$.D Lecturer at National Institute of Transport \\ ${ }^{3}$ Ph.D Lecturer at Open University of Tanzania
}

\section{ARTICLE INFO}

\section{Keywords:}

E-Procurement

Adoption

Model

\begin{abstract}
The objective of this study was to fill the knowledge gap through analyzing the buyers' and suppliers' perception on legal framework influence towards e-procurement adoption model in developing countries, Tanzania in particular. This study was guided by Unified Theory of Acceptance and Use of Technology and the Technology, Organization and Environment model. The study adopted positivism philosophy and cross-sectional survey research design. The study also used non-probability (purposive) sampling and probability (stratified) sampling techniques. Sample size was 157. Questionnaires and documentary review were used for data collection. The collected data were analysed by using Partial Least Squares Structural Equation Modelling (PLS-SEM) with the help of SmartPLS 3 software. Findings reveal that in the presence of performance expectancy, relative advantage and attitude, legal framework has an indirect influence towards e-Procurement Adoption Model. The findings and recommendations of this study are anticipated to improve the adoption of e-Procurement in developing countries, Tanzania in particular.
\end{abstract}

\section{Introduction}

\subsection{Overview and Problem Setting}

Many countries around the world are increasingly becoming focused on improving their public procurement systems both in terms of their legal framework and their practical procedure (Schooner et al., 2008). In developing countries particularly in Tanzania, there has been a tremendous paradigm shift towards e-procurement adoption in public sector due to the fact that e-procurement system has gained a reputation of being one of the most effective way to advance its performance in attaining sustainable procurement (URT, 206; Iles, 2017). Jeptoo and Karanja (2017) emphasize that the public sector organizations which adopted eprocurement system have been able to increase efficiency, transparency, save operations/administration cost and reduce corruption in public services. However, implementing of e-procurement in developing countries is still young (Watuleke, 2017) and in the Tanzanian public sector it is still at operational stage of some features of e-procurement (URT, 2019).

The empirical study by Watuleke (2017) revealed that the success of any new technology (for example e-procurement) adoption requires mutual perception of stakeholders (buyers and suppliers) on important critical success factors which influence the adoption of the new technology. The critical success factors include : for example coercive pressure (legal framework) of the country influences new technology adoption decisions (Tornatzky and

\footnotetext{
* Corresponding Author E-Mail Address: deusshatta@gmail.com
} 
Fleischer, 1990; Suleiman, 2015) perceived performance expectancy of the system influences new technology adoption decisions (Venkatesh et al., 2003); relative advantage (perceived benefits) of the system influences new technology adoption decisions (Tornatzky and Fleischer,1990; Rogers, 2003; Suleiman, 2015); the attitude of top management and users towards implementation of the new system influence new technology adoption decisions (Tornatzky \&Fleischer, 1990;Kassim \& Hussin, 2013; Suleiman, 2015).

With respect to e-procurement adoption initiatives in Tanzania, the government, beginning in the mid-1990s, has initiated a number of procurement reforms in its public procurement system with the aim of making it more efficient and transparent (URT, 2012). In addition, the government has been undertaking reforms in the public procurement legal framework, by amending the Public Procurement Act (PPA) 2004 and its Public Procurement Regulations (PPR) 2005 with the aim of supporting e-procurement adoption which is more efficient and transparent in terms of its performance and benefits (URT, 2016)). The amendments of PPA 2004 and PPR 2005 in 2011 led to the implementation of Tanzanian National e-Procurement System (TANePS) in 2018 because the current Public Procurement Act (PPA) 2011 and its amendment of 2016 supports e-procurement adoption in public sector. Likewise, the current Public Procurement Regulation 2013 and its amendment of 2016 attentions the adoption of eprocurement in public sector. TANePS was piloted in 81 selected procuring entities situated in Arusha, Dar es Salaam, Dodoma, Mbeya and Mwanza during the financial year 2017/2018 (Public Procurement Regulatory Authority (URT, 2018). In addition, 257 staff from 81 procuring entities and 1056 suppliers of goods were trained for piloting the system during the financial year 2017/2018 (URT, 2018).

Nevertheless, at the time of piloting TANePS, the Public Procurement Regulatory Authority (PPRA) Annual Performance Evaluation Report for 2017/2018 financial year revealed that only 730 (69.1 per cent) of the trained suppliers registered in TANePS and 326 (30.9 per cent) of the trained suppliers were reluctant to register in TANePS due to different perception (URT, 2018). Additionally, over 60 per cent of the selected procuring entities for piloting TANePS were not implementing the system during the financial year 2017/2018 and 2018/2019 (URT 2019).

Regardless of the training which had been conducted by PPRA to empower procuring entities' staff (procurement experts) and suppliers on the use and application of TANePS during the financial year 2018/2019 and 2019/2020 respectively, the rate of adoption of the new public procurement system in all selected procuring entities in Tanzania is still unconvinced. This situation is alarming to failure of TANePS adoption initiatives and needs attention to be paid to comprehend scientifically the existing challenges for its adoption in the country.

With regard to the paradigm shift towards the adoption of e-procurement in the Tanzanian public sector, it is important for the government leaders and policy makers to have a framework of analysis for decision making regarding buyers' and suppliers' perception on influence of legal framework towardsTANePS adoption. This is due to the fact that in experimenting with new procurement system (for example TANePS), government leaders and policy makers need a framework of analysis for decision making pertaining to stakeholders' interests and stakeholders' interests should play role in decision making in terms of public procurement system design, development, and reform (Schooner et al., 2008). With that note, this study was guided by Unified Theory of Acceptance and Use of Technology (UTAUT) by Venkatesh et al. (2003); and the Technology, Organization and Environment model (TOE) by Tornatzky and Fleischer (1990).

\subsection{Objective of the Study}

The objective of this study was to analyze the buyers' and suppliers' perception on legal framework influence towards TANePS adoption in the presence of performance expectancy, 
relative advantage and attitude as mediators and important critical success factors which influence the adoption of the new technology.

\subsection{Model Construct and Hypotheses}

The study involved four endogenous constructs and one exogenous construct. Endogenous constructs included performance expectancy from UTAUT by Venkatesh et al. (2003), relative advantage (perceived benefits), attitude from TOE model by Tornatzky and Fleischer (1990) as well as TANePS adoption. The exogenous construct was legal framework from TOE because this study supports the argument that countries are increasingly improving their public procurement systems first (amending legal frameworks first) and then their practical procedures towards e-procurement adoption in public sector (Schooner et al., 2008). That means, legal framework is regarded as dominant critical success factor which influences other critical success factors towards e-procurement adoption in public sector. On the other hand, performance expectancy of the system determines the benefits (relative advantage) of the system because this study supports the argument that e-procurement system has gained a reputation of being one of the most effective way in attaining sustainable procurement, efficiency and transparency in terms of its performance and benefits it brings to the public procurement processes (URT, 2016; Iles, 2017). Lastly, change of attitude of buyers and suppliers depends on understanding of the performance and relative advantage of the system because this study supports the argument that despite the performance and benefits of eprocurement, some buyers and suppliers do hesitate to use the system due to diverse perceptions (Latif, 2014; URT, 2018). Whether these assertions are valid or not valid in relation to paradigm shift to e-procurement adoption in public sector, it was something valuable and worth testing their validity in real life and in relation to the concepts from theorical and empirical studies. For that matter, a number of direct and indirect relationships of determinants were conceptualised as depicted in the conceptual model Figure 1.

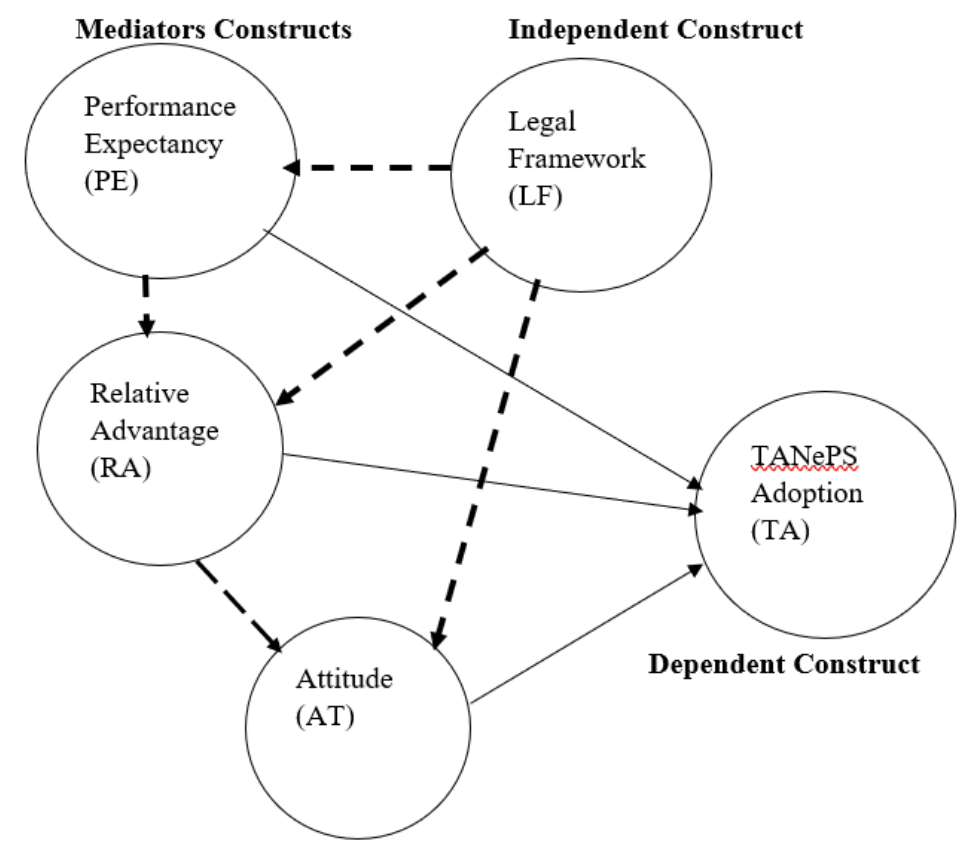

Key

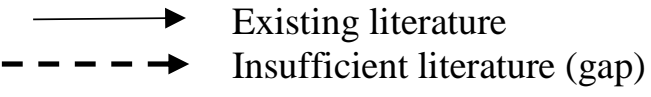

Figure 1. Theoretical Model on Legal Framework Influence Towards TANePS Adoption. Source: Conceptualized from Literature Review, 2020. 


\section{Hypotheses Generated from Theoretical Model Based on Influence of Legal Framework}

$\mathrm{H}_{1 \mathrm{a}}$ : In the presence of Performance Expectancy (PE), Legal framework (LFs) positively and indirectly influences TANePS adoption in the public sector.

$\mathrm{H}_{1 \mathrm{~b}}$ : In the presence of Relative Advantages (RA), Legal framework (LFs) positively and indirectly influences TANePS adoption in the public sector.

$\mathrm{H}_{1 c}$ : In the presence of Attitude (AT), Legal framework (LFs) positively and indirectly influences TANePS adoption in the public sector.

\section{Methods}

This study adopted positivism philosophy and cross-sectional survey research design. The study also used non-probability (purposive) sampling and probability (stratified) sampling techniques. Questionnaires with closed ended questions and documentary review were used for data collection. The collected data were analyzed by using Partial Least Squares Structural Equation Modelling (PLS-SEM) with the help of SmartPLS 3 software. Targeted population was 987 of whom 730 were suppliers who were trained and registered in TANePS and 257 were procurement experts who were trained with regard to TANePS application (URT, 2019). The study used one hundred fifty-seven (157) respondents for data analysis from whom 100 were procurement experts and 57 were suppliers. Justification of the sample size used based on the rule of thumb suggested by Hair et al. (2014) for applying PLS-SEM and SmartPLS 3 software in data analysis which requires number of indicators of the exogenous latent construct (with maximum indicators) times ten equals to be the minimum number of the sample size for the research model to be tested its relationships of constructs and indicators (Hair et al., 2018). In this study, only 40 respondents were required to fulfil the minimum requirement for data analysis by using PLS-SEM with the help of Smart PLS 3 software because the exogeneous latent construct of the research model (legal framework) had four indicators. The number of procurement experts and suppliers used in this study exceed the minimum number of respondents required in each case per rule of thumb suggested by Hair et al. (2014). However, PLS-SEM offers extensive potential for analyzing large datasets, therefore, respondents more than 40 in each case was considered as potential for data analysis in this study.

\section{Findings}

\subsection{Relevance of the Path Coefficients}

Figure 2 shows the relevance of the path coefficients of the research model. In this study, the path coefficients of all hypothesized relationships were positive which meant that an increase in one standard deviation of the critical success factors translated into increase of the rate of TANePS adoption. 


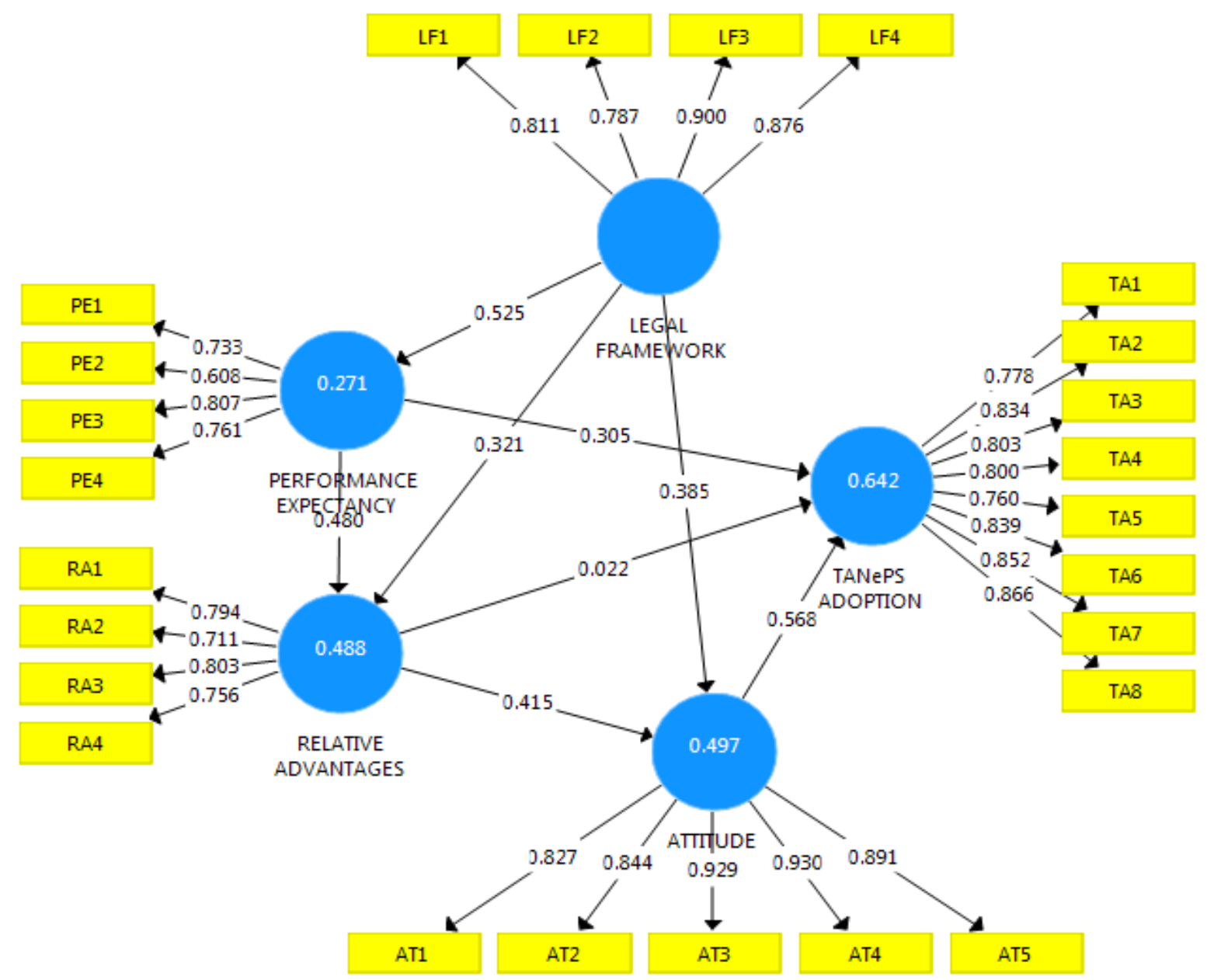

Figure 2. Relevance of the Path Coefficients

\subsection{Statistical Significance of the Hypothesized Relationships}

After executing PLS bootstrapping, the report revealed that one direct hypothesized relationship was rejected which meant does not exist in real life. The results in figure 3 show the hypothesized relationships of the constructs. 


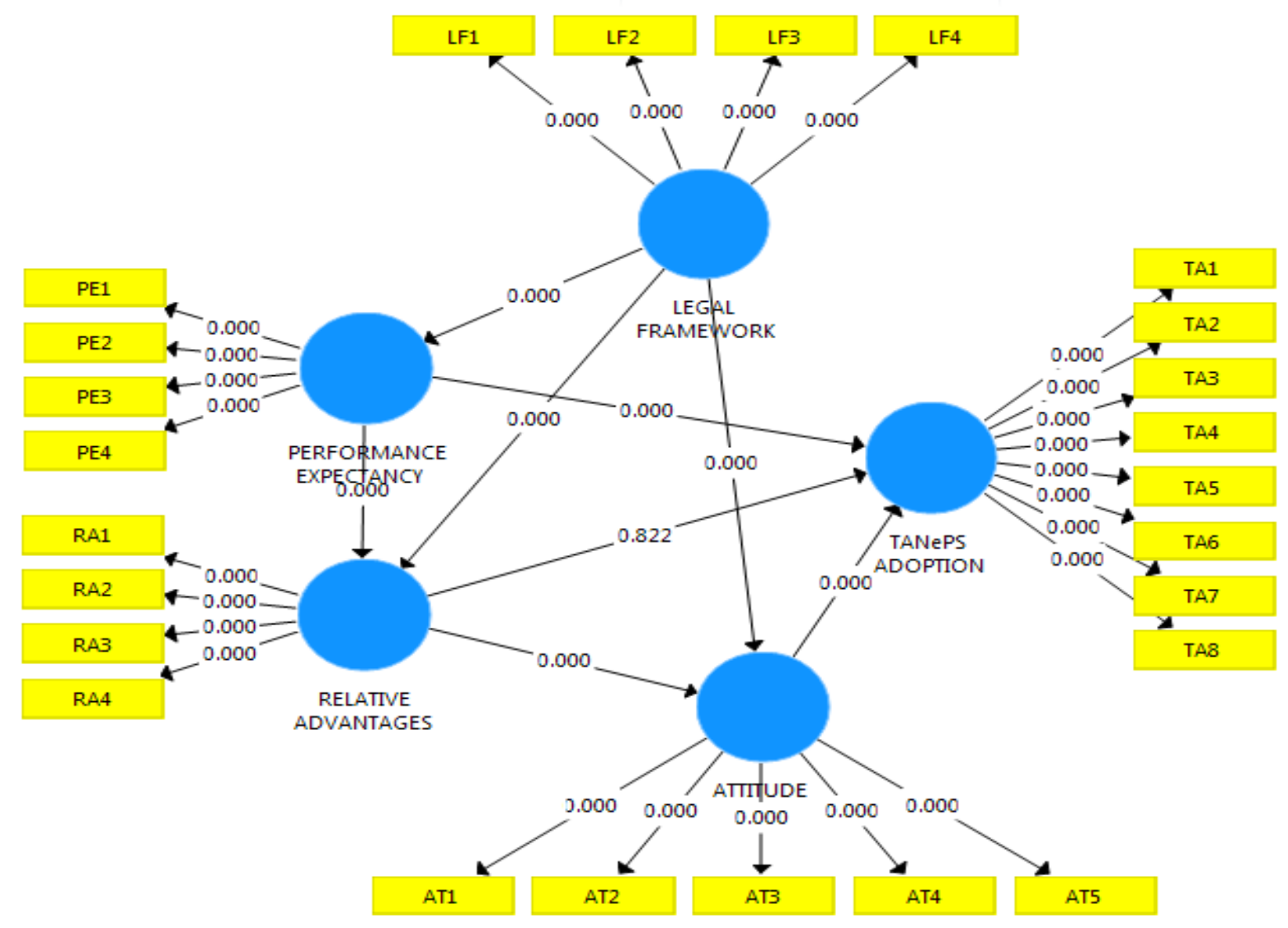

Figure 3. Statistical Significance of the Hypothesized Relationships

Table 1.

Findings of Hypotheses from the Proposed Theoretical Model

\begin{tabular}{llcl}
\hline Hypothesis & Path & P-Value & Remark \\
\hline H1a & LF->PE -> TA & 0.000 & Accepted \\
H1b & LF-> RA -> TA & 0.000 & Accepted \\
H1c & LF ->AT-> TA & 0.000 & Accepted \\
\hline
\end{tabular}

LF=Legal Framework; PE= Performance Expectancy;

RA=Relative Advantage; $\mathrm{AT}=$ Attitude and TA= TANePS Adoption

\section{Discussion of Findings}

\subsection{Validity of the Theoretical Model}

Basing on the findings of this study, the proposed theoretical model is valid for decision making due to the fact that, seven (7) out of eight (8) hypotheses were found statistically significant which meant that 87.5 per cent of the hypothesized relationships exist in real life. Therefore, this model is valid for studies related to buyer-supplier perspective or buyer perspective, or supplier perspective in evolution of the public procurement process from traditional to eprocurement context. Additionally, the model is valid when researchers use a method for data analysis which accommodates direct and indirect relationships like PLS-SEM with the help of SmartPLS 3 software. However, validity of this model is not limited to the geographical area in the world. Figure 4 Shows the final theoretical model with regard to legal framework influence towards TANePS adoption and its implications. 


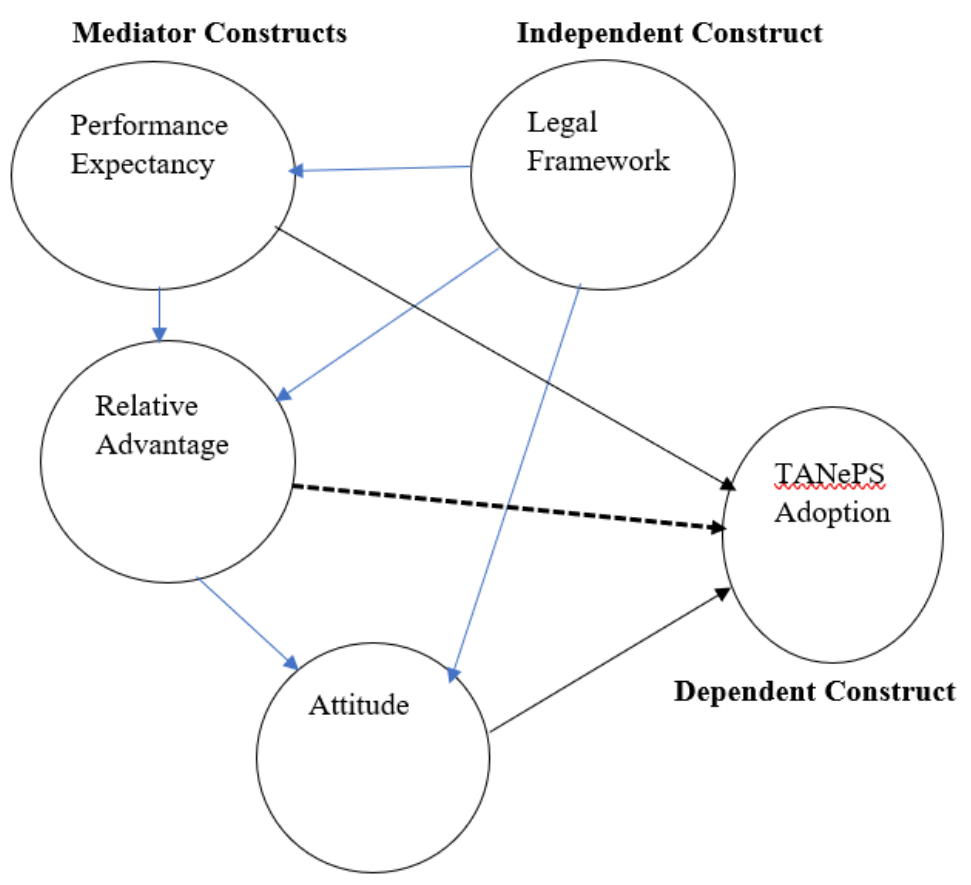

Key

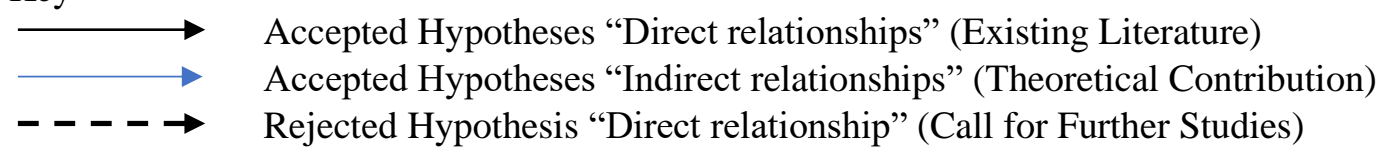

Figure 4. Legal Framework Influence Towards TANePS Adoption. Source: Validated Conceptualized Model, 2020

Basing on flexibility of the theoretical model of this study in terms of accommodating public and private gains in adopting new technologies, it is therefore regarded as contribution to the body of knowledge because the previous theoretical models are clarifying this flexibility inadequately. For example, the Technological-Organizational-Environmental (TOE) model by Tornatzky and Fleischer (1990) has been used to study adoption of innovations and is relevant in the study of technology adoption at the organizational level for public gains (Masele, 2014). However, the main contribution of TOE is that it encourages the researchers to take the broader context into account in which innovation takes place (ibid).

In addition, the 'Unified Theory of Acceptance and Use of Technology (UTAUT)' was developed by Venkatesh et al. (2003) and is useful in studies that explore innovation adoption by individuals for private gains. However, UTAUT does not accommodate legal framework as one of its determinants in adopting new technologies for public or private gains of which the model of this study has clarified this flexibility adequately hence filling the existing theoretical gap.

\subsection{Influences of Legal Framework (LF) on TANePS Adoption}

Legal framework was postulated to positively and indirectly influence TANePS adoption in public sector through performance expectancy, relative advantage and attitude. The findings were positively and statistically significant ( $\mathrm{p}$-value $=0.000$ ). These findings are similar to the previous studies like the study by Azanlerigu and Akay (2015) on prospects and challenges of e-procurement in some selected public institutions in Ghana. The results of this study revealed that legal framework is a basis of any business transaction whether in public sector or private businesses. This is due to the fact that, legal framework defines the obligations and 
responsibilities of the partners transacting business with the objectives of fulfilling each other's desired goal. However, the weakness of the legal framework may inhibit the adoption and growth of e-procurement initiatives (Azanlerigu and Akay, 2015).

The study by Masele (2014) on Adoption of Green E-Business Applications for Sustainable Tourism Development in Developing Countries the Case of Tanzania argued that coercive pressure (legal framework) may include; strict regulations, policies, sanctions and penalties against unfriendly behaviors. The study by Masele (2014) postulated that coercive pressure has influence on organization's commitment towards Green E-Business adoption. Thus, the higher it is, the more likely the organization dedicates itself towards being "green" in using EBusiness. The findings were as follows: $\mathrm{p}=0.003, \mathrm{CR}=2.992$. The $\mathrm{p}$-value of 0.003 and the C.R of 2.992 (which is >1.96) indicated that the relationship was very significant. The study by Masele (2014) proved beyond reasonable doubt that coercive pressures are inevitable if commitment towards Green E-Business adoption was to be instructed for serving public benefits.

Above all, the TOE model also postulated coercive pressures (legal framework) to influence new technologies adoption in public sector for public gains. Although these findings of the current study are similar with some other previous studies on technology adoption for public benefits, this study has added new knowledge with regard to the influence of legal framework on new technology (TANePS) adoption in two perspective; public and private sector gains of which the existing theories and empirical studies are revealing vainly. The critical success factor of legal framework from TOE to influence positively and indirectly the adoption of new technology (TANePS) in public sector after interacting with performance expectancy from UTAUT, is a substance which is missing in the existing literature.

\section{Conclusion}

\subsection{Theoretical Contribution of the Study}

Basing on the theoretical gap and the hypothesized relationships of the determinants of adoption of new technology from UTAUT (performance expectancy) and TOE model (legal framework, relative advantage and attitude), it is therefore concluded that the gap identified has been filled which leads to the theoretical (philosophical) contribution in the existing theories. The interaction and relationships between performance expectancy from UTAUT and legal framework, relative advantage and attitude from TOE model has been sufficiently comprehended in this study a substance that the existing literature was missing. Furthermore, the integrated theoretical model with critical success factors influencing positively and indirectly the adoption of new technology (TANePS) for buyer's and supplier's perspective has been well comprehended in this study of which the existing theories and theoretical models are clarifying inadequately.

\subsection{Empirical Contribution of the Study}

Basing on the focus of previous empirical studies conducted in developing countries and the focus of this study, it is therefore concluded that the empirical gap which was existing has been filled due to the fact that, this study has included both the perception of buyers (procurement experts from public sector) and suppliers (from private sector) on new technology (TANePS) adoption a substance that the existing empirical literature was explaining insufficiently. Additionally, the use of PLS-SEM with the help of SmartPLS 3 software in this study for data analysis is regarded as contribution to the empirical studies of which the method and tool previously were ignored for data analysis. The final integrated model of this study is useful in the process of adding new knowledge to the existing literature when conducting researches related to buyer-supplier perspective and would have practical implications in terms of public procurement policy implementation and applicability of TANePS in the public sector. 


\subsection{Practical Implications of the Study}

Basing on the relationship of the legal framework with other critical success factors influencing TANePS adoption, the final integrated model of this study suggests that, legal framework should not be used directly in the process of adopting new technology (eg TANePS) particularly when suppliers (private sector) are involved in Government business. Instead the legal framework should be used indirectly after significant change of the mindset of the politicians, traditional suppliers, the top management of all procuring entities and the procurement experts working with procuring entities. The significant change of the mindset can be done through training with regard to the performance expectancy and the benefits of TANePS it brings to the supplier community, and also to the government.

\subsection{Recommendations to the Government of Tanzania}

The Government must have a clear strategy to overcome the barriers to change of some stakeholders' attitude and must have greatest commitment towards the adoption of TANePS in all procuring entities of the country. Part of the strategy is to involve in a severe assessment of the current situation of the TANePS adoption in all procuring entities whose staff (procurement experts and IT experts) have been trained on the use and interact with the system.

\section{Acknowledgments}

The researchers wish to acknowledge Prof. Joseph Hair and Prof. Christian Ringle for their facilitations on quantitative data analysis workshop conducted at University of Dar es Salaam Business School in Tanzania. All facilitators enabled the researchers to acquire knowledge and skills of which they have used to analyze the data and write this paper.

\section{References}

Azanlerigu, J.A. \&Akay, E. (2015). Prospects and challenges of e-procurement in some selected public institutions in Ghana. European Journal of Business and Management 7, (29).

Hair, J. F., Ringle, C. M. and Sarstedt, M. (2014). PLS-SEM: Indeed a silver bullet. The Journal of Marketing Theory and Practice, 19 (2), 139-152.

Hair, J.F., Risher,J.J., Sarstedt, M. \& Ringle, C.M. (2018). When to use and how to report the results of PLS-SEM. European Business Review, Permanent link to this document: https://doi.org/10.1108/EBR-11-2018-0203

Iles, J. (2017). How is e-procurement related to the success of U.S. Cities' Sustainable Purchasing Policies? Arizona State University, ASU School of Sustainability

Jeptoo, N. \& Karanja, K. (2017). Effect of governance structure on e-procurement implementation by state corporations in Kenya. International Academic Journal of Procurement and Supply Chain Management, 2(3), 76-91

Kassim, E. S. \& Hussin, H. (2013). A success model for the malaysian government eprocurement system: the buyer perspective. International Journal of Electronic Government Research (IJEGR), 9, (1).

Latif, F. B. (2014). The Adoption of Electronic Procurement in Turkey. Advances in Economics and Business, 2, (2), 85-91.

Masele, J. J. (2014). Adoption of green e-business applications for sustainable tourism development in developing countries the case of Tanzania.A Thesis Submitted to the Department of Business Informatics I, VLBA-University of Oldenburg in Partial Fulfilment of the Requirements for the Award of Degree of Doctor of Philosophy 
Rogers, E.M. (2003). Diffusion of Innovations ( $5^{\text {th }}$ edition), Free Press, New York.

Schooner, L. S., Gordon, I. D. \& Clark, L. J. (2008). "Public Procurement Systems: Unpacking Stakeholder Aspirations and Expectations". GW Law Faculty Publications and Other Works. Paper 111

Shale, N. I. (2014). Role of e-procurement strategy on the performance of state corporations in Kenya. A Thesis Submitted to the School of Entrepreneurship and Procurement Management in the College of Human Resource Development in Partial fulfilment of the Requirements for the Award of Degree of Doctor of Philosophy in Business Administration (Procurement and Supply Chain Management) of Jomo Kenyatta University of Agriculture and Technology

Suleiman, M. (2015).Adoption of e-procurement and value addition: Tanzanian context. European Journal of Business and Management, 7, (14).

Tornatzky, L. \& Fleischer, M. (1990). The Process of Technology Innovation, Lexington, MA, Lexington Books

United Republic of Tanzania (2019). Public Procurement Regulatory Authority Annual performance evaluation report for 2018/2019 financial year

United Republic of Tanzania (2018). Public Procurement Regulatory Authority Annual performance evaluation report for 2017/2018 financial year

United Republic of Tanzania (2016). National Information and Communications Technology Policy, Government Printers, Dar es Salaam.

United Republic of Tanzania (2013). Public Procurement Regulations of 2013 and its amendment 2016, Government Printers, Dar es Salaam.

United Republic of Tanzania (2012). The National Public Procurement Policy, Government Printers, Dar es Salaam.

United Republic of Tanzania (2011). Public Procurement Act (Act No. 21) of 2011 and its amendment 2016, Government Printers, Dar es Salaam.

Venkatesh, V., Morris, M. G., Davis, G. B. \& Davis, F. D. (2003). User acceptance of information technology: Toward a Unified View", MIS Quarterly, 27, (3): 425-478.

Watuleke, J. (2017). E-procurement: evolution and adoption. a review of literature, IJRDOJournal of Educational Research: 2456-2947. 


\section{Appendix}

Cronbach's Alpha, Composite Reliability and AVE Results

\begin{tabular}{lccc}
\hline & $\begin{array}{c}\text { Cronbach's } \\
\text { Alpha }>0.7\end{array}$ & $\begin{array}{c}\text { Composite } \\
\text { Reliability }>0.7\end{array}$ & $\begin{array}{c}\text { Average Variance Extracted } \\
(\text { AVE })>0.5\end{array}$ \\
\hline AT & 0.93 & 0.947 & 0.783 \\
LF & 0.865 & 0.908 & 0.713 \\
PE & 0.711 & 0.819 & 0.534 \\
RA & 0.767 & 0.851 & 0.588 \\
TA & 0.929 & 0.941 & 0.668 \\
\hline
\end{tabular}

Heterotrait-Monotrait Ratio (HTMT) $<0.90$

\begin{tabular}{lcccc}
\hline & AT & LF & PE & RA \\
\hline LF & 0.692 & & & \\
PE & 0.727 & 0.658 & & \\
RA & 0.745 & 0.697 & 0.854 & \\
TA & 0.82 & 0.565 & 0.79 & 0.675 \\
\hline
\end{tabular}

Collinearity Statistics (VIF) for Inner Model $<5$

\begin{tabular}{lllll}
\hline & AT & PE & RA & TA \\
\hline AT & & & & 1.865 \\
LF & 1.488 & 1 & 1.38 & \\
PE & & & 1.38 & 1.917 \\
RA & 1.488 & & & 2.063 \\
\hline
\end{tabular}

$\mathrm{R}^{2}$ Value of the Endogenous Constructs

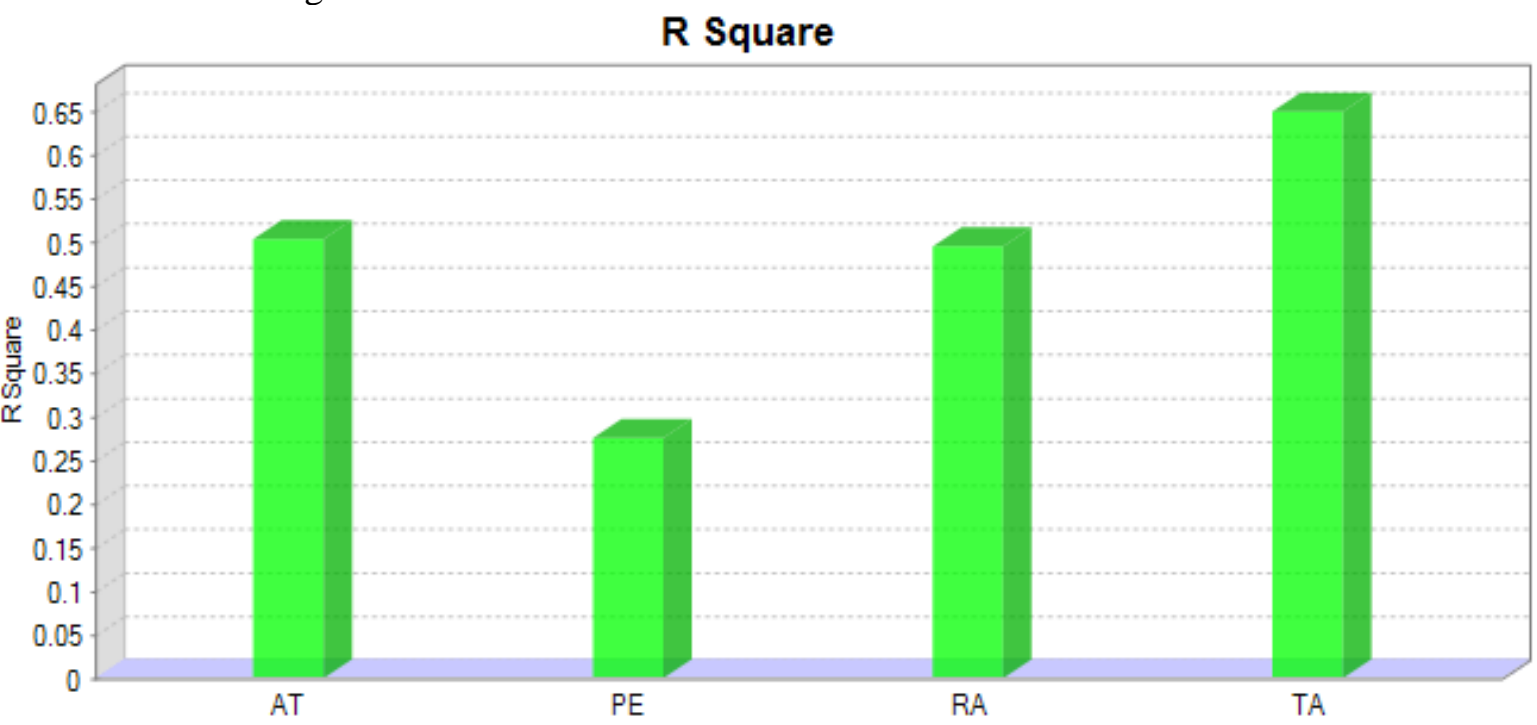

f Squared $>0.02$

\begin{tabular}{lcccc}
\hline & AT & PE & RA & TA \\
\hline AT & & & & 0.494 \\
LF & 0.2 & 0.38 & 0.148 & \\
PE & & & 0.33 & 0.139 \\
RA & 0.233 & & & $\mathbf{0 . 0 0 1}$ \\
\hline
\end{tabular}


Q Square Values for Endogenous Construct

\begin{tabular}{lccc}
\hline & SSO & SSE & $\mathbf{Q}^{\mathbf{2}}(=\mathbf{1}-\mathbf{S S E} / \mathbf{S S O})>\mathbf{0}$ \\
\hline AT & 770 & 488.372 & 0.366 \\
LF & 616 & 616 & \\
PE & 616 & 534.739 & 0.132 \\
RA & 616 & 458.506 & 0.256 \\
TA & $1,232.00$ & 738.824 & 0.4 \\
\hline
\end{tabular}

\section{Path Coefficients}

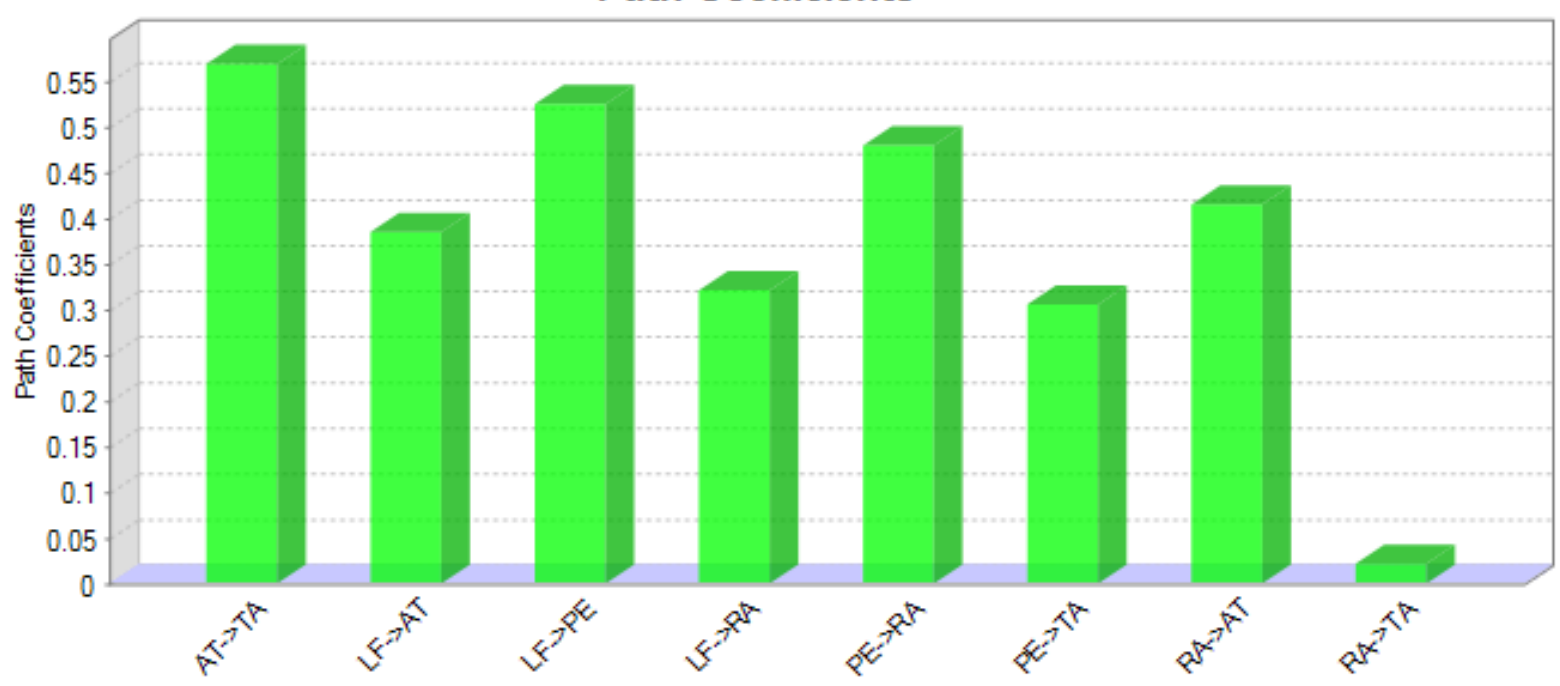

